\title{
Effect of nursing intervention program using abdominal palpation of Leopold's maneuvers on maternal-fetal attachment
}

\author{
Miyuki Nishikawa ${ }^{1 *}$ and Hisataka Sakakibara ${ }^{2}$
}

\begin{abstract}
Background: The aim of this study was to investigate whether a nursing intervention program using abdominal palpation would improve maternal-fetal relationships of pregnant women.

Methods: The subjects were Japanese women aged less than 40 years with singleton pregnancies. A nursing intervention involving abdominal palpations of Leopold's Maneuvers was performed for the intervention group $(n=35)$ in the 30th, 32nd, and 34th weeks' gestation, while ordinary health-related advice was provided to the control group $(n=73)$ in the corresponding period.
\end{abstract}

Results: At the 30th (baseline) week, no intergroup differences were observed. However, the intervention group showed higher Prenatal Attachment Inventory (PAI) scores in the 34th $(P<0.01)$ and 36th weeks $(P<0.05)$ as well as a higher frequency of talking to the fetus in the 32nd $(P<0.01)$, 34th $(P<0.01)$, and 36th weeks $(P<0.05)$. Furthermore, Fetal position awareness score in the 32nd, the 34th, and the 36th weeks were higher in the intervention group than in the control group $(P<0.001)$.

Conclusions: The present findings have suggested that nursing interventions involving abdominal palpations can develop the maternal-fetal relationship. Further random controlled trials are warranted to ascertain this observation.

Keywords: Pregnancy, Nonrandomized trial, Maternal-fetal attachment, Abdominal palpation, Fetal position awareness

\section{Background}

Maternal-fetal attachment is defined as a mother's affiliation with her child [1]. The development of maternalfetal attachment greatly affects the postnatal child-care environment and child development [2-4]. It may influence mother-infant attachment after delivery and the maternal ability to care for the infant [5-7]. Hence, nursing interventions on expectant mothers are important for supporting the development of maternal-fetal attachment.

In Japan, the number of consultations for child abuse has been increasing in recent years [8], and children who are 3 years or younger account for approximately $80 \%$ of the children who die, with 0 -year-old infants

\footnotetext{
* Correspondence: m-nishikawa@mail.koka.ac.jp

'Department of Nursing, Kyoto Koka Women's University, 38 Kadono-cho, Nishikyogoku, Ukyo-ku, Kyoto, 615-0882 Japan

Full list of author information is available at the end of the article
}

accounting for $60 \%$. The main abusers of children are their mothers, and it is of primary importance that child abuse is identified at an early stage. A strong correlation has been reported between high-risk children and child abuse [9]. Higher maternal-fetal attachment would be necessary to be developed by nursing care in the pregnancy period.

There are several studies to report effective intervention programs for the development of maternal-fetal attachment in expectant mothers, such as an intervention using fetal palpation [10], offering the knowledge of the child care for couples [11], providing information and teaching stress management methods [12], expressing affection to the fetus by writing letters and talking [13], and having singing, dancing, and massage-through-thewomb sessions [14]. Meanwhile, it is indicated that the attachment to the fetus can be enhanced by sensitive maternal perception of fetal movements [15-18] and 
positive child imaging [19-21]. Maternal-fetal attachment is also known to be associated with quickening of the fetus closely [22,23]. Additionally, Shin et al. (2006) showed that more active mother-child interactions during pregnancy caused higher maternal attachment to the fetus [7]. Thus, nursing interventions to let mothers actively interested in the fetus may lead to higher maternal attachment to the fetus.

The abdominal examination method of Leopold's Maneuvers is a way to determine the position of a fetus inside the uterus by touching the abdomen by hands. This method is expected to enable expectant mothers to perceive the fetal position, and stimulate the awareness of child presence. Hence, we considered that a nursing intervention program using this abdominal palpation method might be useful for the enhancement of maternal-fetal attachment. The aim of this study was to investigate whether a nursing intervention program using abdominal palpation of Leopold's Maneuvers would improve maternal-fetal relationships of pregnant mothers.

\section{Methods}

\section{Study setting and participants}

The study subjects were singleton pregnant Japanese women under the age of 40 in two women's hospitals that are under the same management in Shiga, Japan. Because the study started at the 30 weeks of gestation, the participants were recruited from women who were 16 to 28 weeks gestation. They had regular prenatal care at the hospitals, and their pregnancies were progressing normally. The exclusion criteria were pregnant women who were having any complications related to the mother or fetus (for example, low-lying placenta, placenta previa, pregnancy-induced hypertension, intrauterine growth restriction, etc.), pregnancies resulting from advanced assisted reproductive technology, and single mothers. They were recruited from December 2009 through August 2010.

All subjects participated in this study after signing the written consent. This study protocol was approved by the Ethics Committee of Nagoya University School of Medicine.

\section{Assignment method}

Of the total of 384 pregnant women in the target weeks' gestation, 227 (59.1\%) agreed to participate in the study. Of those 227 subjects, 88 wished to participate in an intervention program. Thereby, they were non-randomly assigned to the intervention group $(n=88)$ or the control group $(n=139)$. In the intervention group, of the initial 88 subjects, 42 did not actually participate in the study at all. Of the 46 participants, seven women participated only once, because two were directed to rest by a physician, one was under hospitalized supervision due to threatened premature delivery, one withdrew due to breech presentation, and three were busy with other duties. Four women participated two times, because one delivered prematurely, two were ordered to rest by a physician due to threatened premature delivery, and one was in poor physical condition. In the end, 35 women participated in the intervention program all three times and completed the questionnaire survey for the 36th week. In the control group of 139 women, 108 completed the questionnaire during the first survey, but 73 during fourth survey. As a result, the final analysis was conducted for 35 (76\%) of 46 participants to the first intervention program in the intervention group and 73 (68\%) of 108 participants to the first control program in the control group (see Figure 1).

\section{Procedures}

All pregnant women at the hospitals were expected to participate in a pre-mothers' class to learn about general health care during the pregnancy a total of 3 times at the 30th, 32nd, and 34th weeks' gestation. Hence, subjects in the intervention group were to participate in both the pre-mothers' classes and additional intervention programs involving abdominal examinations. Those in the control group were supposed to participate in the pre-mothers' class (the control program) only. The intervention program (and the control program) was then performed at the 30th, 32nd, and 34th weeks' gestation.

At the women's hospitals in this study, all participants regularly received prenatal examinations including ultrasound examinations performed by a physician, and necessary health advice for normal pregnancies from midwives.

\section{Intervention program}

The intervention program was intended to help the pregnant participants to sense the fetal position in the uterus by touching the abdomen by performing an abdominal examination of Leopold's Maneuvers. Following the pre-mothers' class (the control program), the nursing intervention program was conducted by three midwives. Midwives explained the fetal position by taking the hand of each participant and touching the buttocks and the back of the fetus together, so that expectant mothers were actually able to touch their abdomens and the large and small body parts of the fetuses. After the practice was completed, a group discussion was held for about 20 min with all of the participants regarding whether they were able to sense the position of the fetus, their thoughts toward the fetus, and so on. Each intervention program took approximately 1 to $1.5 \mathrm{~h}$.

The control group participated in the pre-mothers' classes. At the study institution, pre-mother classes are 


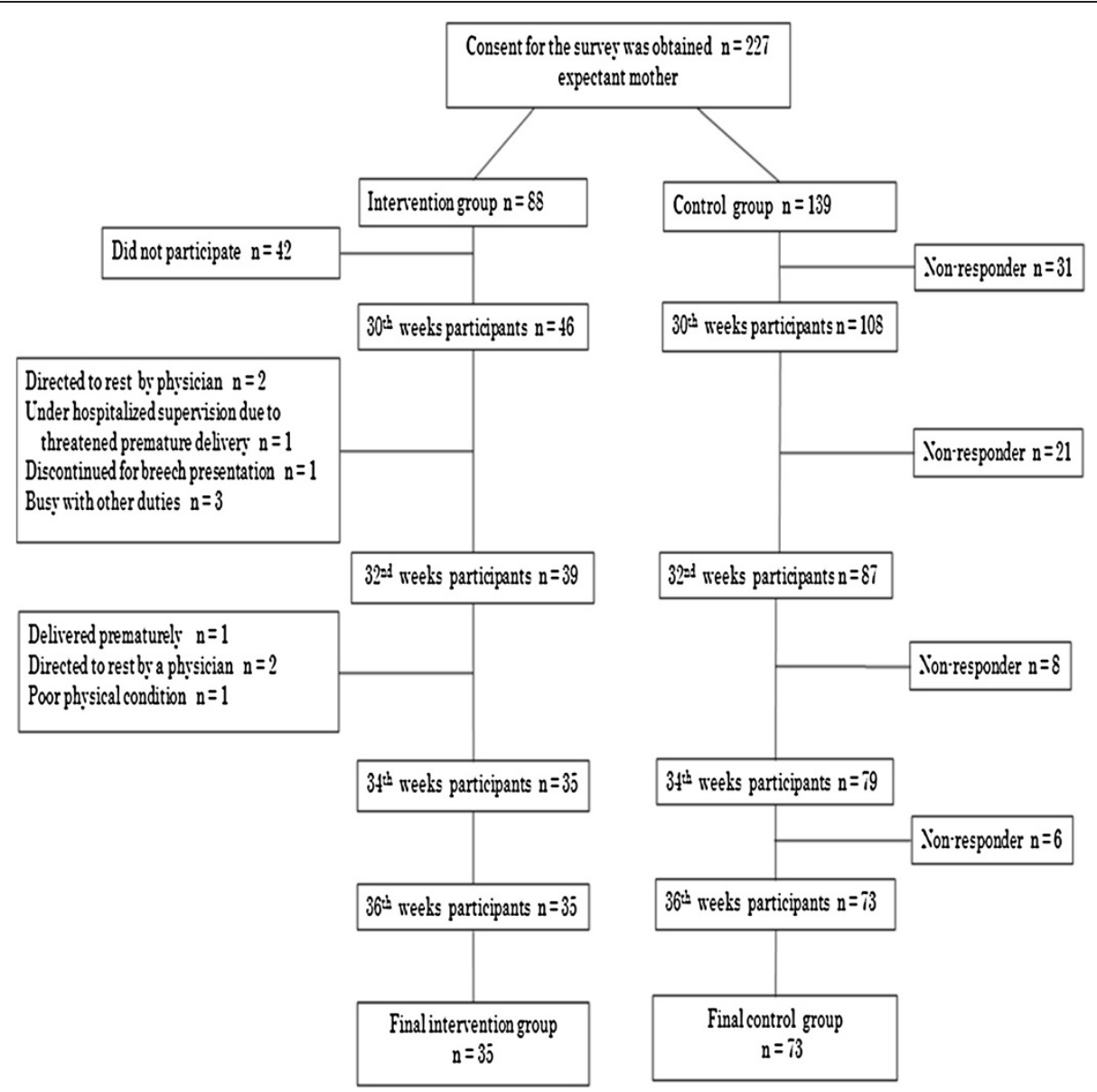

Figure 1 Schematic representation of study's sampling method.

held 3 times from the second trimester to the last trimester of pregnancy. The pre-mothers' classes generally provide information on general health care during pregnancy, such as nutritional intake and daily life, prenatal exercise, preparation for child birth and mental attitude, methods to alleviate delivery labor, infant bathing techniques, and they are also an opportunity to make friends with other participants. Each pre-mothers' class is held for about $1.5 \mathrm{~h}$. These classes for expectant mothers are common at most of the institutions in Japan.

\section{Measurements}

A self-completed questionnaire survey of the same contents was conducted in the intervention group and the control group at the 30th (baseline), 32nd, 34th, and 36th weeks' gestation. In the intervention group, subjects completed the questionnaire after practicing the abdominal palpation in the intervention program at the 30th, 32nd, and 34th weeks' gestation. The survey at the 36th week was done by mail. In the control group, the questionnaire survey was conducted by mail 4 times at the same times as the intervention group. The present study was conducted from November 2009 to December 2010.

The questionnaire covered demographic characteristics, attachment to the fetus, frequency of talking to the fetus, and awareness of the position of the fetus.

For demographic characteristics, the following questions were asked: age, spouse's age, primigravida or multigravida, nuclear family or extended family, unplanned or planned pregnancy, employed or unemployed, and educational background (to select from junior high-school graduate, high-school graduate, junior college graduate, or graduate of university or higher).

The relationship between the expectant mother and the fetus was examined using the PAI by Muller [24]. We used the Japanese version of the PAI by Tujino [25]. The PAI consists of a 21-item scale that is designed to measure the behavior and feelings of an expectant mother toward the fetus. Each item has 4 Likert-type responses: 4 points are given for "almost always," 3 points for "often," 2 points for "sometimes," and 1 point for "almost never." The total score ranges between 21 and 84 . A higher score is indicative of a higher attachment to 
the fetus. The Japanese-language version of the PAI has been validated for Japanese women [25]. The Cronbach's alpha of PAI were 0.89 .

The question regarding the frequency of talking to the fetus was as follows: "How many times did you talk to your fetus every day during the last week on average?" The frequency of talking to the fetus is thought to reflect the maternal attachment to the fetus [19-21].

The questionnaire about the awareness of the position of the fetus was intended to measure to what degree expectant mothers perceive the fetus position in the uterus. A 6-item scale with 5 Likert-type responses was prepared by the authors to assess maternal awareness of the fetal position: (1) I perceive that the fetus is moving his/her legs; (2) I perceive that the fetus is moving his/ her hands; (3) When I touch the abdomen with my hands, I perceive the position of the back of the fetus; (4) When the fetus moves, I softly touch my abdomen; (5) I imagine the fetus' character from his/her movement; and (6) I can depict the appearance of the fetus. For each item, 5 points are given for "always," 4 points for "frequently," 3 points for "sometimes," 2 points for "occasionally," and 1 point for "almost never." A higher score is expected to show a greater awareness of the fetal position. Internal reliability was examined using Cronbach's alpha coefficient in this study. This was defined as the fetal position awareness score.

\section{Statistical analyses}

Statistical analyses were performed using chi-square tests or Mann-Whitney $U$ tests for categorical variables and Student's $t$ tests for continuous variables. The internal reliability for the questionnaire on PAI and awareness of the fetal position was examined using Cronbach's alpha coefficient. In order to examine the effects of the intervention, Mann-Whitney $U$ tests were employed for comparisons between the intervention group and the control group. For comparison of the time-series data after the intervention, Wilcoxon signed-rank tests were used with a Bonferroni correction because of a 3-time comparison (i.e., of the 30th [baseline] with the 32nd, 34th, and 36th weeks' gestation). All analyses were 2sided with $P$ values less than 0.05 considered statistically significant. The statistical software package SPSS for Windows J ver. 16.0 (IBM Corporation, Armonk, NY, USA) was used.

\section{Results}

As shown in Table 1, the characteristics of the subjects at baseline showed no significant differences in age, family type, unplanned/planned pregnancy, unemployment, and education between the intervention group and the control group. The proportion of primigravidae in the intervention group tended to be higher, although it was not significantly different between the groups. Prenatal attachment or fetal position awareness also did not differ between primigravidae and multigravidae.

As for the Cronbach's alpha coefficient, high internal reliability was verified for the PAI scale $(0.884-0.926)$ and the fetal position awareness score $(0.740-0.854)$ (see Table 2).

Table 1 Characteristics of study subjects $(\mathrm{N}=108)$

\begin{tabular}{|c|c|c|c|c|}
\hline \multirow[t]{2}{*}{ Characteristics } & \multirow[t]{2}{*}{ Category } & \multicolumn{3}{|c|}{ Mean (SD) or $n(\%)$} \\
\hline & & $\begin{array}{l}\text { Intervention group } \\
(\mathrm{n}=35)\end{array}$ & $\begin{array}{l}\text { Control group } \\
(n=73)\end{array}$ & P-value \\
\hline \multirow[t]{2}{*}{ Age in years } & Expectant mother & $30.3(4.7)$ & $31.8(4.7)$ & $0.142^{a)}$ \\
\hline & Spouse & $32.5(6.0)$ & $33.0(4.9)$ & $0.700^{a)}$ \\
\hline \multirow[t]{2}{*}{ Parity } & Primigravida & $26(74.3 \%)$ & $42(57.5 \%)$ & $0.092^{b)}$ \\
\hline & Multigravida & $9(25.7 \%)$ & $31(42.5 \%)$ & \\
\hline \multirow[t]{2}{*}{ Family type } & Nuclear family & $28(80.0 \%)$ & $58(79.5 \%)$ & $0.720^{b)}$ \\
\hline & Extended family & $7(20.0 \%)$ & $15(20.5 \%)$ & \\
\hline Unplanned pregnancy & Yes & $14(40.0 \%)$ & $31(42.5 \%)$ & $0.764^{b)}$ \\
\hline \multirow[t]{2}{*}{ Employment status } & Employed & $16(45.7 \%)$ & $31(42.5 \%)$ & $0.750^{b)}$ \\
\hline & Unemployed & $19(54.3 \%)$ & $42(57.5 \%)$ & \\
\hline \multirow[t]{5}{*}{ Education Level (graduated) } & $<$ High school & $0(0 \%)$ & $3(4.1 \%)$ & $0.440^{b)}$ \\
\hline & High School & $7(20.0 \%)$ & $13(17.8 \%)$ & \\
\hline & Specialty school & $3(8.6 \%)$ & $14(19.2 \%)$ & \\
\hline & Junior college & $10(28.6 \%)$ & $21(28.8 \%)$ & \\
\hline & University or above & $15(42.9 \%)$ & $22(30.1 \%)$ & \\
\hline
\end{tabular}

a) Significance determined by t tests between the intervention group and the control group.

b) Significance determined by chi-square tests between the intervention group and the control group. 
Table 2 Internal reliability (cronbach's a) for PAI score and fetal position awareness score $(N=108)$

\begin{tabular}{|c|c|c|c|}
\hline Variable & Investigation & Median (IQR) & Cronbach's a \\
\hline \multirow[t]{4}{*}{$P A I^{a)}$} & 30th week & $53(46,61)$ & 0.884 \\
\hline & 32nd week & $57(49,63)$ & 0.886 \\
\hline & 34th week & $58(50,64)$ & 0.907 \\
\hline & 36th week & $59(52,66)$ & 0.926 \\
\hline \multirow{4}{*}{$\begin{array}{l}\text { Fetal position awareness } \\
\text { score }\end{array}$} & 30th week & $18(15,21)$ & 0.740 \\
\hline & 32nd week & $20(16,23)$ & 0.765 \\
\hline & 34th week & $21(17,24)$ & 0.826 \\
\hline & 36th week & $22(18,25)$ & 0.854 \\
\hline
\end{tabular}

a) $P A l$, Prenatal Attachment Inventory score.

At the baseline of the 30th weeks' gestation, the PAI score and the fetal position awareness score did not differ between the intervention group and the control group. Similarly, the frequency of talking to the fetus was not different between both groups at baseline (see Table 3).

After the intervention programs, the PAI score in the intervention group was raised significantly at the 32nd, 34th, and 36th weeks' gestation compared to baseline $(P<0.01)$. Similarly, the control group showed an increase in the PAI scores at the 32nd, 34th, and 36th weeks' gestation $(P<0.05$ or $P<0.01)$. Because the score increased more in the intervention group, significant differences between both groups were seen at the 34th and 36 th weeks $(P<0.01$ and $P<0.05$, respectively).

The frequency of talking to the fetus in the intervention group also increased to be greater at the 32nd, 34th, and 36th weeks' gestation than at baseline $(P<0.01)$. In the control group, a significant increase was found at the 34th and 36th weeks' gestation $(P<0.01$ and $P<0.05$, respectively). Then, the frequency of talking to the fetus was higher in the intervention group than in the control group at the 32nd, 34th, and 36th weeks $(P<0.05$ or $P<0.01)$.

Meanwhile, the maternal awareness score of fetal position increased to be significantly greater in the intervention group at the 32nd, 34th, and 36th weeks' gestation than at baseline $(P<0.01)$, as well as at the 34th and 36th weeks' gestation in the control group $(P<0.05$ and $P<0.01$, respectively). The score in the intervention group was then significantly higher than that of the control group at the 32nd, 34th, and 36th weeks' gestation $(P<0.001)$ (see Table 3$)$.

\section{Discussion}

In the present study, the PAI score and the frequency to talk to the fetus in the intervention group increased more greatly during pregnancy and were greater after the 32th week or the 34 weeks' gestation than in the control group. The maternal awareness score of fetal position was also higher in the intervention group after the 32nd weeks' gestation. Thus, the present nursing intervention using abdomen palpation was shown to be effective for promoting maternal-fetal attachment in normal expectant mothers.

At the 30th weeks' gestation (the baseline), there were no differences in the PAI score, the frequency of talking to the fetus, the fetal position awareness score, and the social backgrounds between the intervention group and the control group. It is known that the PAI scores are affected by age, marital status, parity, planned pregnancy, and education, and the like [26]. In this study those were

Table 3 Changes of maternal-fetal relationship by nursing intervention using abdominal palpations

\begin{tabular}{|c|c|c|c|c|}
\hline \multirow[t]{2}{*}{ Variable } & \multirow[t]{2}{*}{ Investigation } & \multicolumn{2}{|c|}{ Median (IQR) } & \multirow[t]{2}{*}{$P$-value ${ }^{b)}$} \\
\hline & & Intervention group $(n=35)$ & Control group $(n=73)$ & \\
\hline \multirow[t]{4}{*}{$\overline{\mathrm{PAl}}{ }^{\mathrm{a})}$} & 30th week & $54(47,62)$ & $53(45,61)$ & 0.546 \\
\hline & 32nd week & $57(54,65)^{* *}$ & $56(49,63)^{* *}$ & 0.149 \\
\hline & 34th week & $61(55,70)^{* *}$ & $57(50,62)^{*}$ & 0.006 \\
\hline & 36th week & $64(57,69)^{* *}$ & $58(51,63)^{* *}$ & 0.021 \\
\hline \multirow[t]{4}{*}{ Frequency of talking to the fetus per day } & 30th week & $3(2,6)$ & $3(2,5)$ & 0.330 \\
\hline & 32nd week & $5(3,10)^{* *}$ & $3(2,5)$ & 0.004 \\
\hline & 34th week & $5(3,10)^{* *}$ & $4(2,6)^{* *}$ & 0.005 \\
\hline & 36th week & $5(3,10)^{* *}$ & $4(2,5)^{* *}$ & 0.015 \\
\hline \multirow[t]{4}{*}{ Fetal position awareness score } & 30th week & $19(16,22)$ & $18(15,21)$ & 0.270 \\
\hline & 32nd week & $22(20,24)^{* *}$ & $19(15,22)$ & $<0.001$ \\
\hline & 34th week & $24(21,27)^{* *}$ & $18(16,23)^{*}$ & $<0.001$ \\
\hline & 36th week & $24(22,27)^{* *}$ & $21(17,23)^{* *}$ & $<0.001$ \\
\hline
\end{tabular}

${ }^{*} p<0.05,{ }^{* *} p<0.01$ by the Wilcoxon signed-rank test compared to the 30th week (baseline)

a) $P A l$, Prenatal Attachment Inventory score.

b) Significance determined by Mann-Whitney $U$ tests between the intervention group and control group. 
not different between both groups, so that both groups under study were considered to have similar social backgrounds.

Pregnant mothers of the normal pregnancy process naturally develop attachment to the fetuses as pregnancy progresses $[16,17,27,28]$. Gestational age is reportedly the most powerful predictor of maternal-fetal attachment [26]. In this study as well, the maternal attachment to the fetus increased in both groups as pregnancy progressed. However, the PAI scores in the intervention group increased more greatly than in the control group, and the scores of the former subjects were significantly higher after the 34th week of pregnancy than those of the latter. Similarly, the frequency to talk to the fetus was also greater in the intervention group after the 32nd week, which may partly reflect increased maternal-fetal attachment. These findings have demonstrated that the present intervention program improved maternal-fetal attachment.

The present intervention program was designed to facilitate the fetal position awareness of expectant mothers through abdominal examinations of Leopold's Maneuvers. Earlier studies have suggested that maternal-fetal attachment develops especially after quickening of the fetus [22], and that a mother's sensitive perception of fetal movements contributes to enhancing attachment to the fetus [15-18], though a recent study did not show the effectiveness of fetal movement counting on attachment [29]. It can be easier to sense fetal movement through the abdominal wall than with the central nervous system $[30,31]$. In this nursing intervention program, midwives explain the fetal position by taking the hand of each participant and touching the head or the buttocks of the fetus. Such touching of the abdominal wall with midwives to perceive the fetal position could lead to more sensitive perception of fetal activity than fetal movement counting. Actually, the intervention increased the maternal awareness of the fetal position as well as maternal-fetal attachment. These findings suggest that maternal awareness of the fetal position or movements through abdominal palpation could serve to strengthen maternal-fetal attachment. Nursing interventions that enhance fetal position awareness may be an effective method for developing maternal-fetal attachment.

It is also known that maternal attachment toward the child develops during the pregnancy by talking to the fetus or imagining the fetus [32]. Enhanced maternal awareness of the fetal position by abdominal palpation may further promote expectant mothers to feel the fetal presence, imagine the fetus figure, and communicate with the fetus, resulting in the development of maternal attachment to the fetus. In addition, social support is a moderate powerful predictor of maternalfetal attachment [26]. The present intervention program might have partly worked as social support to pregnant women.

O'Connor et al. (2002) indicated that low socioeconomic status, symptoms of depression, and fewer social resources of expectant mothers and families affect the mother-child relationship [33]. The present subjects were recruited from expectant mothers with normal social backgrounds. The effects of this intervention to high-risk subjects need to be investigated among pregnant women with high-risk backgrounds.

\section{Study strengths and limitations}

The participants were not randomly assigned to the intervention group or the control group. Hence, there may have been a bias to the motivation of the study participants. In addition, the dropout rates after the study started were $23.9 \%$ of 11 expectant mothers in the intervention group and $32.4 \%$ of 35 expectant mothers in the control group, though the dropouts were due to medical, social, or personal reasons. One of the reasons may be due to a gap of 4 to 6 weeks between the time of obtaining informed consent and that of starting investigation. However, there were no differences in the social backgrounds and maternal-fetal attachment between two groups at baseline.

Maternal-fetal attachment was assessed using a selfreported questionnaire of the PAI. The maternal awareness of the fetal position was measured with an original questionnaire. Their reliability was examined using the Cronbach's alpha coefficient. They both showed high internal reliability.

The present subjects were 35 women in the intervention group and 73 in the control group, who were recruited in two women's hospitals that are under the same management. Further RCT studies using more subjects from multiple institutions would be desirable to ascertain the present findings.

\section{Conclusions}

The present findings have suggested that nursing intervention using abdominal palpations of Leopold's Maneuvers can enhance maternal awareness of fetal positions, maternal-fetal attachment and the frequency of the mother talking to the fetus. Further random controlled trials are warranted to ascertain this observation.

\section{Competing interests}

The authors declare that they have no competing interests.

\section{Authors' contributions}

Both authors were responsible for designing, data processing, statistical analysis, interpretation and writing up the final article and gave the final approval of the manuscript to be published.

\section{Acknowledgments}

We would like to express our gratitude to Dr Yoshiki Jinno and the staff of the hospital. We also would like to thank Ms. Chitaka Saito, Ms. Miho Tanaka, 
and Ms. Rumiko Nakagawa, who were the midwives who supported this nursing intervention.

\section{Author details}

'Department of Nursing, Kyoto Koka Women's University, 38 Kadono-cho, Nishikyogoku, Ukyo-ku, Kyoto, 615-0882 Japan. ${ }^{2}$ Nagoya University Graduate School of Medicine, 1-1-20 Daiko-minami, Higashi-ku, Nagoya 461-8673, Japan.

Received: 6 October 2012 Accepted: 14 February 2013

Published: 19 February 2013

\section{References}

1. Cranley MS: Development of a tool for measurement of maternal attachment during pregnancy. Nurs Res 1981, 30(5):281-284.

2. Ainsworth MDS: Attachment and dependency: a comparison. In Attachment and dependency. Edited by Gewirtz JL. Washington, D.C: V. H. Winston \& Sons; 1972:97-137.

3. Bowlby J: Attachment theory and its therapeutic implications. Adolesc Psychiatry 1978, 6:5-33.

4. Bronfenbrenner U: Ecology of the family as a context for human development research perspectives. Dev Psychol 1986, 22:723-742.

5. Mercer RT, Ferketich SL: Predictors of maternal role competence by risk status. Nurs Res 1994, 43(1):38-43.

6. Cannella B: Maternal-fetal attachment: an integrative review. J Adv Nurs 2005, 50(1):60-68.

7. Shin H, Park Y-J, Kim MJ: Predictors of maternal sensitivity during the early postpartum period. J Adv Nurs 2006, 55(4):425-434.

8. Ministry of health, labour, and welfare, Japan, information on children and childrearing: http://www.mhlw.go.jp/english/wp/wp-hw4/dl/equal_employ ment_and_child_welfare/2011071920.pdf

9. Leventhal JM, Garber RB, Brady CA: Identification during the postpartum period of infants who are at high risk of child maltreatment. J Pediatr 1989, 114(3):481-487.

10. Carter $\mathrm{J}$ : Promoting maternal attachment through prenatal intervention. MCN 1981, 6:107-112.

11. Bryan A: Enhancing parent-child interaction with a prenatal couple intervention. MCN 2000, 25(3):139-144.

12. Schachman KA, Lee RK, Lederma RP: Baby boot camp: facilitating maternal role adaptation among military wives. Nurs Res 2004, 53(2):107-115

13. Chang S, Park S, Chung C: Effect of Taegyo-focused prenatal education on maternal-fetal attachment and self-efficacy related to childbirth. $J$ Korean Acad Nurs 2004, 34(8):1409-1415.

14. Bellieni CV, Ceccarelli D, Rossi F, Buonogore G, Maffel M, Perrone S, Petraglla $\mathrm{F}$ : Is prenatal bonding enhanced by prenatal education courses? Minerva Ginecol 2007, 59(2):125-129.

15. Mikhail MS, Freda MC, Merkatz RB, et al: The effect of fetal movement counting on maternal attachment to fetus. Am J Obstet Gynecol 1991, 165(4 Pt 1):988-991.

16. Zachariah R: Maternal-fetal attachment: influence of mother-daughter and husband-wife relationships. Res Nurs Health 1994, 17(1):37-44.

17. Bloom KC: The development of attachment behaviors in pregnant adolescents. Nurs Res 1995, 44(5):284-288.

18. Saastad E, Ahlborg T, Frøen JF: Low maternal awareness of fetal movement is associated with small for gestation age infant. J Midwifery Womens Health 2008, 53(4):345-352

19. Fonagy $\mathrm{P}$, Steele $\mathrm{H}$, Steele M: Maternal representations of attachment during pregnancy predict the organization of infant-mother attachment at one year of age. Child Dev 1991, 62(5):891-905.

20. Huth-Bocks AC, Levendosky AA, Bogat GA, von Eye A: The impact of maternal characteristics and contextual variables on infant-mother attachment. Child Dev 2004, 75(2):480-496.

21. Theran SA, Levendosky AA, Bogat A, Huth-Bocks AC: Stability and change in mothers' internal representations of their infants over time. Attach Hum Dev 2005, 7:253-268.

22. Bloom KC: Perceived relationship with the father of the baby and maternal attachment in adolescents. JOGNN 1998, 27(4):420-430.

23. Salisbury A, Low K, LaGasse L, Lester B: Maternal-fetal attachment. JAMA 2003, 289(13):1701.

24. Muller ME: Development of the prenatal attachment inventory West J Nurs Res 1993, 15(2):199-215.
25. Tsujino J, Oyama M, Inuihara T: The relationship of maternal attachment towards children before and after their birth and the factors that influence maternal atttachment: an analysis using the knowledge discovery method. [In Japanese]. J Clin Educ Psychology 2000, 26(1):35-40.

26. Yarcheski A, Mahon NE, Yarcheski TJ, Hanks MM, Cannella BL: A metaanalytic study of predictors of maternal-fetal attachment. Int J Nurs Stud 2009, 46(5):708-715

27. Wailand J, Tate S: Maternal-fetal attachment and perceived relationship with important others in adolescents. Birth 1993, 20(4):198-203.

28. Berryman JC, Windridge KC: Pregnancy after 35 and attachment to the fetus. J Reprod Infant Psychol 1996, 14(2):133-143.

29. Saastad E, Ahlborg T, Frøen JF: Fetal movement counting-effects on maternal-fetal attachment: a multicenter randomized controlled trial. Birth 2011, 38(4):282-293.

30. Rubin R: Maternal identity and the maternal experience. New York: Spring Publishing Co; 1984.

31. Tuffnel DJ, Cartmill RSV, Lilford RJ: Fetal movements - factors affecting their perception. Eur J Obstet Gynecol Reprod Biol 1991, 39(3):165-167.

32. Mercer RT: Becoming a mother: research on maternal role identity since Rubin. New York: Springer Co; 1995

33. O'Connor TG, Heron J, Golding J, Beveridge M, Glover V: Maternal antenatal anxiety and children's behavioural/emotional problems at 4 years-report from the Avon longitudinal study of parents and children. Br J Psychiatry 2002, 180:502-508.

doi:10.1186/1742-4755-10-12

Cite this article as: Nishikawa and Sakakibara: Effect of nursing intervention program using abdominal palpation of Leopold's maneuvers on maternal-fetal attachment. Reproductive Health 2013 10:12.

\section{Submit your next manuscript to BioMed Central and take full advantage of:}

- Convenient online submission

- Thorough peer review

- No space constraints or color figure charges

- Immediate publication on acceptance

- Inclusion in PubMed, CAS, Scopus and Google Scholar

- Research which is freely available for redistribution
C Biomed Central 